\title{
Research on water environment problems of Liaohe Basin and treatment countermeasures
}

\author{
Fei Li \\ the Party School of Liaoning Provincial Government \\ Shenyang, China 110004 \\ bjlifei@163.com
}

Keywords: Liaohe basin, Water environment, Treatment countermeasures.

Abstract. The features of economic social development and urban layout of Liaohe Basin result in heavy water pollution, difficult treatment and many remaining problems with features of structural, compound and regional pollution. We should adjust the develop strategy, underline industrial harmony, emphasize environment protect and optimize industrial structure, with an emphasis on high efficiency and on the premise of ecological environment protect, optimize the water resources distribution, while strengthen the prevention and control of agricultural non-point pollution source, determine an intensive farming, enhance the control of farmland surface runoff pollution, improve the treatment rate of waste water, strengthen the management of sewage.

\section{Introduction}

Liaohe basin is one of the seven major rivers in China, is the lifeblood of economic and social development in northeast China. As of the leading position for revitalization of northeast old industrial base, Liaohe basin is also an important economic zone of Liaoning and even of the whole country. The features of economic social development and urban layout of Liaohe Basin result in heavy water pollution, difficult treatment and many remaining problems with features of structural, compound and regional pollution. Liaohe basin is included in the three rivers which are mainly controlled for water pollution since the ninth five-year. With years' endeavor, water quality of Liaohe mainstream made some good change in the end of the eleventh five-year; however, the pollution condition was not improved fundamentally. The thirteenth five-year is a vital stage for comprehensive revitalization of northeast old industrial base and the development of Liaoning economic. The rapid development of economic society will certainly bring huge pressure on the water environment, while the water resources and water environment will also be the key factors which restrict the development of social economic. Therefore, to research the current situation and existing problems of Liaohe basin and propose efficient countermeasures of water environment management has important realistic significance.

\section{Water environment problems of Liaohe basin}

Water quality has made a good change, qualified rate of section COD goes upCOD pollution of Liaohe mainstream is significantly reduced since 2009. COD concentration of mainstreams of Liaohe, Hunhe, Taizihe and Daliaohe is decreased by 5.5\%-59.4\% on year-on-year basis; in 41 main branches, concentration of $58.5 \%$ is decreased by $17.3 \%-84.5 \%$, while rate of branch COD which exceeds standard is $26.8 \%$. Average annual COD of sections of Liaohe mainstream has meet the grade V standard; water quality of dry season in 2013 was the best among the last three years, during which average annual COD of all sections in dry season meet grade $\mathrm{V}$ water quality standard for the first time.

Quantity of pollutants of the basin is large, and the total amount has exceeded the capacity of water environment.

With the endeavor during ninth five-year to twelfth five-year, water pollution of Liaohe basin has been efficiently controlled, and water quality has got certain improvement. However, even when water 
quality is qualified, the COD of mainstreams of Liaohe basin is 206,000 ton/year, while NH3-N is 8,866 ton/year.

Actual emissions of COD and NH3-N are 300,000 ton and 35,000 ton respectively in 2013, exceeding 0.5 and 3.3 times of the water environment capacity. Therefore, the pollution of Liaohe basin has the feature of high intensity and large load, while main pollutants' emission is significantly larger than the water environment capacity. The water environment is still in overload condition.

\section{NH3-N pollution is severe}

Although the treatment of Liaohe has obtained some success, the water quality pollution is still severe. NH3-N has been the primary polluting factor. Constant improvement of water quality is facing a big challenge. Qualified rate of NH3-N concentrations of sections in Liaohe mainstreams is low, and average annual value shows a trend of fluctuations. During 2009-2013, percentages of mainstream sections of which NH3-N meet the grade V standard are 15.4\%, 38.5\%,15.4\%, 34.6\% and 30.8\% respectively. NH3-N pollution at Tieling Sanhetun section is the heaviest in 2012 along the Liaohe basin, 2.2 times higher than the standard; pollution is reduced when flowing to Shenyang, while flowing to Panjin and receiving industial waster water and sewage, NH3-N content of the Shuguang Bridge section is 1.0 times higher than the standard. NH3-N pollution increases gradually along the Hunhe; NH3-N of four sections in Shenyang are all beyond the normal range, in which the section of Shashan is heaviest, 3.2 times higher than the standard. COD of the whole Taizihe meets the III type water quality standard, but because of exceeded NH3-N content, water quality is changed from grade II in upstream to grade V; NH3-N of three sections in Anshan are 0.9-1.3 times higher. Three sections of Daliaohe after joining in of Hunhe and Taizihe are all worse than grade V, NH3-N of Sanchahe is 1.5 times higher. Pollution situation of Daliaohe flowing to Yingkou is reduced affecting by the tide, NH3-N of sections of Heiyingtai and liaohe Park of downstream are 0.6 times and 0.4 times higher than the standard.

\section{Water environment pollution shows the regional and industrial characters.}

Liaoning is the famous domestic old industrial base, with almost 60 years history of traditional industries, having a regional pollution character in the basin. Industrial As emission in 2012 is 1.27 ton, while major industries are non-ferrous metal mining and chemical raw materials \& chemical products manufacturing, the main emission areas are focused in Daliaohe Yingkou Branch, Hunhe Fushun Branch and Taizihe Liaoyang Branch. Industrial $\mathrm{Hg}$ emission in 2012 is $134.41 \mathrm{~kg}$, while major industries are non-ferrous metal mining and chemical raw materials \& chemical products manufacturing, the main emission areas are focused in Daliaohe Yingkou Branch, and Taizihe Benxi Branch. Industrial Pb emission in 2012 is 1095.26 ton, while major industries are non-ferrous metal mining and metal smelting \& processing, the main emission areas are focused in Taizihe Anshan Branch and Hunhe Shenyang Branch.

\section{Destruction situation of basin ecological environment is terrible}

Unreasonable economic and social activities as well as over-development of water and soil resources, large quantity improper used ecological water, dried-up rivers, degraded wetlands, heavy polluted river sections flowing through cities, biodiversity loss and severely destroyed water environment ecological system of basin, all this result in imbalance of water environment ecological system in the basin (district), making the condition even worse. Biodiversity survey of algas in Liaohe mainstream sections in 2013 shows that: in the 25 sections monitored, clean sections account for $19.2 \%$, sections with light pollution account for $46.2 \%$ and medium pollution-34.6\%. Biodiversity survey of benthos in Liaohe mainstream sections shows that: sections of clean, light pollution, medium pollution and heavy pollution account for $4.5 \%, 36.4 \%, 13.6 \%$ and $45.5 \%$ respectively, in which, the Hunhe Fushun section is of light pollution, Shenyang section-heavy; Laoguanlazi section of Taizihe Benxi Branch and Liaoyang section are of light pollution while others are heavy; all sections monitored in Liaohe are all of heavy pollution. 


\section{Countermeasures and recommendations}

\section{Adjust the develop strategy}

Districts of Liaohe basin are applying optimizing economic structure and transforming economic growth pattern as the principal line, emphasizing industrialization and urbanization level promotion, taking improving the level of people's material and cultural life as starting point and ultimate goal, to drive the economic realizing unusual and leaping development. The develop strategy lays one-sided emphasis on the importance of industry to promote regional social and economic development, pursues rapid development, results in planning deviating from the track of scientific development. Protecting the environment is the prerequisite and essential condition of economic development. Pursuing rapid growth of industry will inevitably bring environmental problems. The development strategy should emphasize industrial harmony and pay attention to environmental protection.

\section{Optimize the industry structure}

Change the current condition of basin which mainly relies on energy resource exploration and manufacturing industry, improve the proportion of high-tech industries, promote industrial structure adjustment and optimization, gradually abandon the "high input, high consumption and high growth" mode, make great efforts to develop ecological industries and new type industries, enhance the resource comprehensive utility, speed up the transformation of economic growth mode. Meanwhile, by industrial parks and industries districts reconstructs the industry layout and structure adjustment, and develops recycling economy.

Energy conservation and emissions reduction is a rigid strategic task put forward by the country in the height of the national economy sustainable development in the phase of transition economy. The key of energy conservation and emissions reduction is economic structure adjustment. With sound industry structure adjustment, the pressure will be greatly relieved. Therefore, districts along Liaohe basin should put emphasis on industries of low input, low consumption, low pollution and high profit, and reduce industries of high input, high consumption, high pollution and low profit; by promoting industries gradient transfer, make a bigger space to develop high-tech industries and advanced manufacturing; for heavy chemical industries with high energy consumption, resource utilization efficiency could be increased through innovation and reformation of technical equipments. In addition, for industries with high consumption such as papermaking and thermal power, principal of approving construction of large scale ones while reducing small ones should be implemented, to accelerate the elimination of backward production capacity, process, technology and equipments.

\section{Carry out water resource strategy}

The average per capita water resource in Liaohe basin is $850 \mathrm{~m} 3$, while the water resource in per acre is only $315 \mathrm{~m} 3$. Water resource is of heavy shortage. High proportion of agriculture, high water consumption and low utilization efficiency cause a highlighted water shortage. The current comprehension utilization of water resources is already very high, so the future situation of water resources and the conflict between supply and demand of water resources will be very serious. To promote the sustainable utilization of water resources has become the strategy issue of each district for a sustainable development of economic and society. Improving the agriculture water utilization efficiency and constructing a water-saving society is the necessary way that each city must apply. Water resources distribution of each district should focus on high efficient utilization, take ecological environment protection as the premise, make full use of the surface water sources; water resources development and utilization is given priority to surface water, while groundwater is complementary. Using reservoir engineering maximizes the adjustment degree of natural surface runoff and the increase of groundwater recharge. Take groundwater as strategic reserve water, exploit groundwater moderately in normal year, and take effective measures to control the exploration of groundwater resources, to ensure the groundwater dynamic balance. Improve the water utilization efficiency sufficiently. In terms of water distribution, apply advanced water conservancy engineering measures, increase the canal seepage control and the construction of water facilities and the low pressure pipeline; in terms of agriculture water utilization, promote water-saving irrigation technology such as spraying, micro-irrigation, dripping, tube filling etc. for dry land crops, while promote water-saving irrigation 
system of 'pale, dry, wet' for rice cultivation, improve the utilization efficiency of irrigation water. Also adjust the crop planting structure and reduce the planting water consumption; in terms of industrial water utilization, improve industrial water reuse rate through the adjustment of industrial structure and the industry management measures of water supply to water consumption quota; in terms of water utilization management, promote the whole society to save water by economic mechanism, and improve water utilization efficiency and benefits.

\section{Strengthen the prevention and control of agricultural non-point pollution source}

Liaohe basin is the famous main grain production areas and major commodity grain production base. With strong husbandry production growth, it is also the animal husbandry production base in Liaoning province. Agriculture of each city accounts for a big proportion in regional economic. Regional environment pollutants load is mainly from agricultural non-point pollution source, especially from the livestock breeding which is of large proportion in non-point pollution load. According to current situation of each city's economic environment, we should actively adopt some measures to prevent and control pollution.

Determine an intensive farming. Intensive farming will benefit for the implementation of pollution prevention principle which is 'priority of comprehensive utilization, resources recovery, harmless and quantity reduction'. We should make full use of the advantage of intensive farming, transfer the non-point pollution source of free range farming to point source pollution for better control.

Improve the treatment rate of waste water, strengthen the management of sewage. Small and medium-sized cities are lack of sewage treatment facilities, thus sewage treatment infrastructure is a priority. We have to improve the urban sewage treatment rate, and increase the intensity of sewage recycling. Unpowered sewage treatment system or land treatment system could be promoted in the countryside. Technologies of economic, simple, effective and combined with local agriculture are suitable for agricultural sewage treatment, and could make the sewage harmless. Rural sewage treatment should insist on applying the ecotype, high stability, low investment, less maintenance and green technology.

Enhance the control of farmland surface flow pollution. Make great effort to develop ecological agriculture, promote agricultural industrial structure adjustment, promote organic agriculture and ecological agriculture, and actively guide farmers to utilize fertilizer and pesticide in a scientific and rational way, advocate and promote the application of organic fertilizer. Combine the farming and forestry, animal husbandry, fishery and related processing organic to establish a new comprehensive agricultural system of ecological rationality, function virtuous cycle and low energy consumption, and achieve economic, ecological and social benefits.

\section{Acknowledgement}

This research was financially supported by the National Social Foundation. general project "Research on the Environmental Effect of Regional Industrial Structure Transformation” (No: 13BJY067)

\section{References}

[1] TANG $\mathrm{Yu}$, Research on the Water Environment Management of Liaohe River Basin,Environmental Protection and Circular Economy, 2007, ( 5 ) : 49-51.

[2] YIN Jinhang et al., Fuzzy Comprehensive Evaluation of Hydro-ecological Health Condition in Dongliao River Basin, ,2012(10):6057-6059.

[3] GAO Yuan-yuan et al., Land Use/Cover Change in Liao River Basin, Journal of Anhui Agricultural Sciences ,2016(2) : 27-30. 